\title{
Clinical Benefits of Low Serum Digoxin Concentrations in Heart Failure
}

\author{
Kirkwood F. Adams, JR, MD, FACC,* Mihai Gheorghiade, MD, FACC,§ Barry F. Uretsky, MD, FACC,\| \\ J. Herbert Patterson, PHARmD,† Todd A. Schwartz, MS,‡ James B. Young, MD, FACC \\ Chapel Hill, North Carolina; Chicago, Illinois; Galveston, Texas; and Cleveland, Ohio
}

\begin{abstract}
OBJECTIVES We sought to determine whether there was a relationship between serum digoxin concentration (SDC), including SDCs typically regarded as low, and clinical efficacy related to digoxin in patients with symptomatic left ventricular dysfunction.

BACKGROUND Digitalis glycosides have been used for 200 years in the treatment of heart failure (HF), but the SDC required for optimal clinical efficacy and acceptable toxicity remains controversial.

METHODS This relationship was investigated by utilizing data from two randomized, double-blinded, placebo-controlled, digoxin-withdrawal trials: the Prospective Randomized study Of Ventricular failure and Efficacy of Digoxin (PROVED) and the Randomized Assessment of Digoxin on Inhibitors of Angiotensin-Converting Enzyme (RADIANCE). Major end points were worsening $\mathrm{HF}$, change in left ventricular ejection fraction and treadmill time after randomization. The primary analysis investigated the relationship between SDC at randomization and these end points. A secondary categorical analysis compared these end points in patients who discontinued digoxin versus patients who continued digoxin and had low $(0.5$ to $0.9 \mathrm{ng} / \mathrm{ml})$, moderate $(0.9$ to $1.2 \mathrm{ng} / \mathrm{ml})$ or high $(>1.2 \mathrm{ng} / \mathrm{ml})$ SDCs at randomization.

RESULTS Multiple regression analysis failed to find a relationship between randomization SDC, considered as a continuous variable, and any study end point (all $\mathrm{p}>0.236$ ). Multivariable Cox analysis found that the risk of worsening HF was significantly less (all $p<0.02$ ) for patients in any category of SDC who continued digoxin, as compared with patients withdrawn from digoxin. Specifically, patients in the low SDC category were significantly less likely than placebo patients to experience worsening $\mathrm{HF}$ during follow-up ( $\mathrm{p}=$ $0.018)$.

CONCLUSIONS The beneficial effects of digoxin on common clinical end points in patients with HF were similar, regardless of SDC. (J Am Coll Cardiol 2002;39:946-53) C) 2002 by the American College of Cardiology Foundation
\end{abstract}

Digitalis glycosides have been used for 200 years in the treatment of heart failure (HF), but the serum digoxin concentration (SDC) required for optimal clinical efficacy and acceptable toxicity remains controversial $(1,2)$. Previous work has established that higher serum concentrations exert greater positive effects on left ventricular (LV) function (3-6). However, the degree of improvement in LV func-

\section{See page 954}

tion, due to digitalis, necessary for a clinical benefit, if any, is unknown. In addition, digitalis appears to exert a favor-

From the Departments of Medicine and Radiology, *School of Medicine and $\dagger$ School of Pharmacy, and $\ddagger$ Department of Biostatistics, School of Public Health, University of North Carolina, Chapel Hill, North Carolina; §Department of Medicine, Northwestern University Medical School, Chicago, Illinois; |Department of Medicine, University of Texas Medical Branch, Galveston, Texas; and the IDepartment of Cardiology, Cleveland Clinic Foundation, Cleveland, Ohio. Work related to the present study was supported in part by the PHS Research Grant MO1 RR00046 from the General Clinical Research Center's branch of the Division of Research Resources, University of North Carolina at Chapel Hill. The PROVED and RADIANCE studies were supported by a grant from Glaxo-Wellcome, Inc., Research Triangle Park, North Carolina.

Manuscript received September 15, 2000; revised manuscript received December 12, 2001, accepted December 21, 2001. able effect on abnormalities of autonomic tone present in $\mathrm{HF}$, which calls into question a pure inotropic mechanism of action for the drug $(7,8)$. Recent work suggests these favorable neurohormonal effects occur at low doses of digoxin (9), and that increasing the SDC beyond modest levels (i.e., $0.7 \mathrm{ng} / \mathrm{ml}$ ) may not produce additional neurohormonal benefits (10).

Despite suggestions from these mechanistic studies that low SDCs might be as effective as higher ones, this work contains few patients and does not provide convincing data on end points of major clinical interest. To gain additional insight into this issue, we applied the results from the Prospective Randomized study Of Ventricular failure and Efficacy of Digoxin (PROVED) and Randomized Assessment of Digoxin on Inhibitors of the AngiotensinConverting Enzyme (RADIANCE) trials $(11,12)$. These randomized trials investigated the effect of digoxin withdrawal on a number of important measures of clinical status, including risk of worsening HF, exercise capacity and LV function. Close monitoring revealed a spectrum of digoxin concentrations in patients randomized to continue the drug throughout follow-up, despite upward titration of the dose 


$$
\begin{aligned}
& \text { Abbreviations and Acronyms } \\
& \begin{array}{ll}
\mathrm{HF} & =\text { heart failure } \\
\mathrm{LV} & =\text { left ventricular } \\
\mathrm{LVEF} & \text { left ventricular ejection fraction } \\
\text { PROVED } & \text { Prospective Randomized study Of } \\
& \text { Ventricular failure and Efficacy of } \\
& \text { Digoxin } \\
\text { RADIANCE }= & \text { Randomized Assessment of Digoxin on } \\
& \text { Inhibitors of the Angiotensin- } \\
& \text { Converting Enzyme } \\
= & \text { serum digoxin concentration }
\end{array}
\end{aligned}
$$

to achieve traditional therapeutic serum concentrations during stabilization. Thus, the results from PROVED and RADIANCE afford a unique opportunity to investigate whether SDC is related to a clinical benefit from digoxin in patients with HF. Our analysis provides significant new information on administration of digoxin in patients with HF.

\section{METHODS}

Design of protocols. The design and conduct of the PROVED and RADIANCE trials were similar, and the details of these studies have been well documented in previous reports $(11,12)$. Briefly, both trials were multicenter, double-blinded, randomized, placebo-controlled, parallel-group, withdrawal studies that utilized the same entry criteria (Fig. 1). Each study began with an eight-week, single-blinded stabilization phase during which the patients' background therapy for HF was optimized. Patients completing the baseline phase were randomized to either continue digoxin or receive placebo instead of digoxin, while trial-specific background therapy was kept constant for as long as possible during follow-up. After randomization, the patients were reassessed in detail regarding their clinical status, exercise capacity and ventricular function. Their SDC was measured at visits 1, 4 and 6 in the baseline phase and at the final study visit by a central laboratory (Smith-

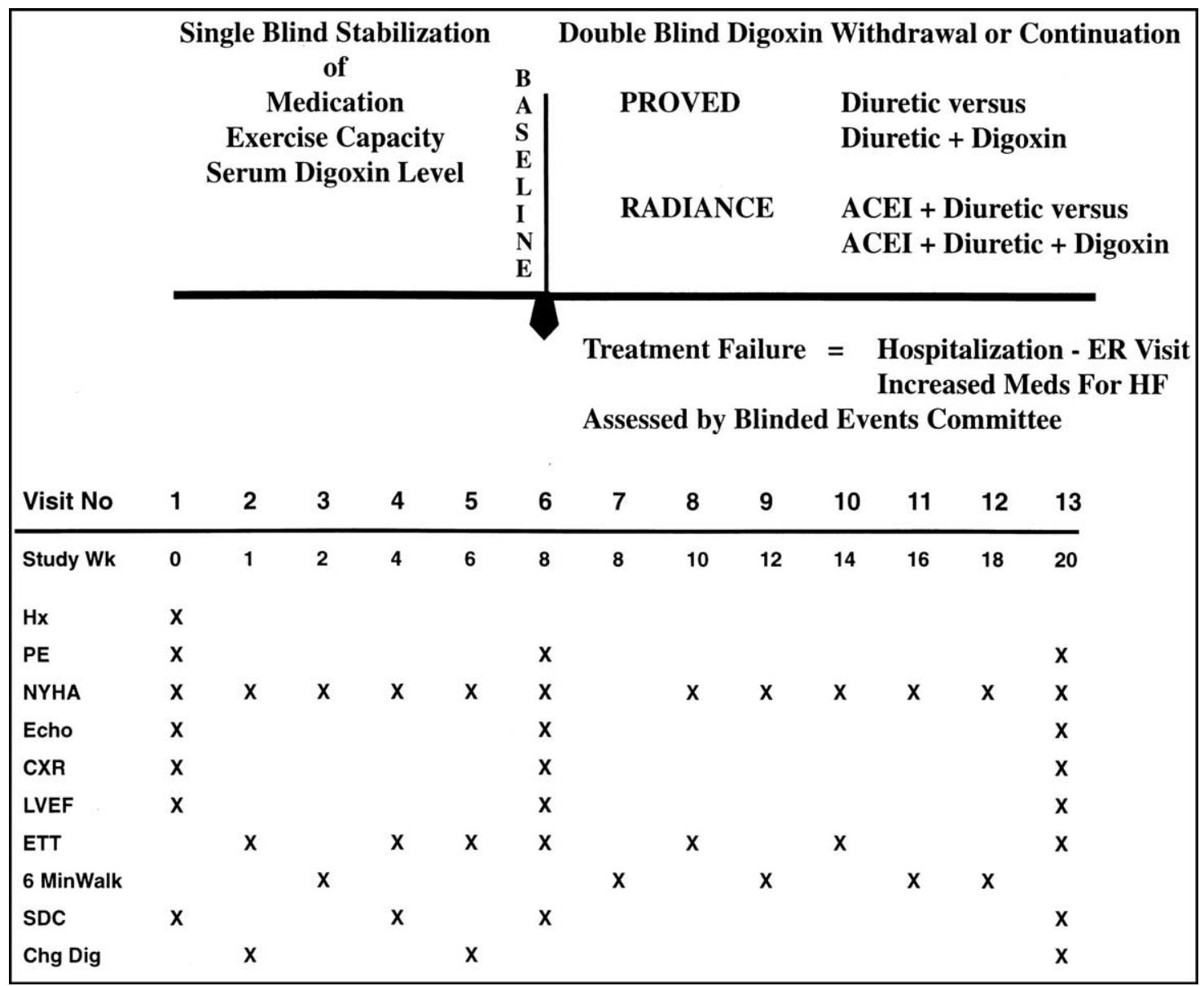

Figure 1. Study schema of the Prospective Randomized study Of Ventricular failure (PROVED) and Randomized Assessment of Digoxin on Inhibitors of the Angiotensin-Converting Enzyme (RADIANCE) trials. After a period of single-blinded stabilization, the patients were randomized to continue or discontinue digoxin, while maintaining background therapy as indicated. The occurrence of treatment failure was determined by an Events Committee that was blinded to treatment assignment. ACEI = angiotensin-converting enzyme inhibitor; $\mathrm{Chg}$ Dig $=$ investigator change in digoxin dose; $\mathrm{CXR}=$ chest $\mathrm{x}$-ray; Echo = echocardiogram; $\mathrm{ER}=$ emergency room; ETT = maximal exercise treadmill test; $\mathrm{HF}=$ heart failure; $\mathrm{Hx}=$ history; LVEF $=$ left ventricular ejection fraction; NYHA = New York Heart Association functional class; $\mathrm{PE}=$ physical examination; $\mathrm{SDC}=$ serum digoxin concentration; Wk $=$ week; 6 MinWalk $=6$-min walk test. 
Kline BioScience). The dose of digoxin was withheld on the day of these protocol visits, so that serum concentrations reflected trough levels of digoxin. Digoxin dose adjustments were made, based on the determination at visit 1 , in an attempt to achieve an SDC of 0.9 to $2.0 \mathrm{ng} / \mathrm{ml}$ by the time of randomization. Digoxin doses were to remain unchanged after randomization, and SDC was measured in a similar fashion at the final study visit.

Analysis of end points. Data from the PROVED and RADIANCE trials were combined for the purposes of this analysis. Both PROVED and RADIANCE compared patients randomized to continue or discontinue digoxin, with regard to the following end points: 1) rates of withdrawal due to worsening HF; 2) time to withdrawal; and 3) changes in exercise capacity, as assessed by treadmill testing or the 6-min walk test. In the present analysis, end points 1 and 2 were evaluated and end point 3 , analysis of exercise capacity, was restricted to treadmill data. In addition, we compared the change in LV ejection fraction (LVEF) from randomization to the last measured value in the study patients.

Statistical analysis. The patient populations of PROVED and RADIANCE were combined for the study analysis. Data are presented as the mean value \pm SEM, unless otherwise indicated. In the principal study analysis, multivariate modeling was used to assess the relationship between SDC at randomization and end points of major interest. Treatment failure was assessed using Cox proportional hazards methods, and change in treadmill exercise capacity and LVEF were assessed by standard multiple regression (13). The following variables were considered as potential predictors of the study end points of interest: the last available SDC at or before randomization, race, age, gender, ischemic versus nonischemic etiology, use of angiotensinconverting enzyme inhibitors, blood pressure, heart rate, jugular venous distension, $\mathrm{S}_{3}$ gallop, rest LVEF, cardiothoracic ratio, exercise tolerance, $\mathrm{LV}$ end-diastolic dimension and HF score. The HF score was determined from the patient's symptoms, signs and chest $x$-ray results collected at the randomization visit, as previously described (14). In addition, digoxin use after randomization was included as a categorical variable to model the effect of digoxin therapy versus no digoxin therapy, regardless of the magnitude of SDC at randomization. Finally, regression analysis was repeated using the final SDC obtained after randomization.

A secondary categorical analysis was performed to assess the relationship between SDC and specific study end points. For this analysis, patients were divided into four subgroups: 1) patients randomized to discontinue digoxin, regardless of SDC at randomization; 2) patients who continued digoxin and were found at randomization to have an SDC in the lowest tertile $(<33$ percentile; $\leq 0.9 \mathrm{ng} / \mathrm{ml}) ; 3)$ middle tertile (33 to 66 percentile; 0.9 to $1.2 \mathrm{ng} / \mathrm{ml}$ ); and 4) highest tertile ( $>66$ percentile; $>1.2 \mathrm{ng} / \mathrm{ml}$ ) at randomization. In this analysis, assessment of the relationship between SDC subgroups and study end points was made by Cox proportional hazards methods for treatment failure and by appro- priate parametric and nonparametric tests for changes in treadmill exercise capacity and LVEF.

\section{RESULTS}

Study patients. Table 1 summarizes the clinical characteristics of the PROVED and RADIANCE patient populations classified into treatment groups based on their SDC at randomization versus patients randomized to discontinue digoxin. These four subgroups of patients from PROVED and RADIANCE had comparable baseline characteristics. Digoxin dose and SDC. The average daily dose of digoxin was $0.22 \pm 0.01 \mathrm{mg} /$ day at the baseline visit, which was associated with a mean SDC of $0.60 \pm 0.04 \mathrm{ng} / \mathrm{ml}$. During the baseline phase, there was an upward titration of the digoxin dose to $0.36 \pm 0.01 \mathrm{mg} / \mathrm{day}$, which was associated with a mean SDC of $1.11 \pm 0.02 \mathrm{ng} / \mathrm{ml}$ by the randomization visit. Only trivial changes in the dose of digoxin were noted among the 77 patients randomized to continue digoxin who had this result available at their final visit. The final mean digoxin dose for these patients was $0.37 \pm$ $0.01 \mathrm{mg} /$ day. Data on SDC at the final visit were available in 116 of the 127 patients randomized to continue digoxin and were very similar to the randomization SDC data for the entire group $(1.13 \pm 0.05 \mathrm{ng} / \mathrm{ml})$. Data in Table 2 show the mean digoxin dose at baseline, randomization and the final study visit for the four subgroups of SDC. The mean values were similar from randomization to the final study visit for the digoxin dose and SDC in each of the four treatment groups.

Multiple regression analysis. Multivariable Cox modeling of the likelihood of treatment failure after randomization failed to associate SDC at randomization with this end point (relative risk [RR] 1.72, 95\% confidence interval [CI] 0.70 to $4.22, \mathrm{p}=0.236$ ). In contrast, there was a strong relationship between continuing or discontinuing digoxin and the occurrence of treatment failure after randomization (RR 0.15 for digoxin vs. no digoxin, $95 \%$ CI 0.07 to 0.32 , $\mathrm{p}<0.0001)$. Likewise, a change in the treadmill duration was not associated with SDC at randomization $(\mathrm{p}=0.855)$ but was significantly related to whether the patient continued or discontinued digoxin during follow-up ( $\mathrm{p}<0.0001)$. There was no relationship between SDC at randomization and a change in $\operatorname{LVEF}(\mathrm{p}=0.274)$, whereas randomization to digoxin or placebo was significantly related to a change in LVEF ( $p<0.0001)$. Multiple regression analysis also failed to find a relationship between final SDC and any end point considered in this analysis (all $\mathrm{p}>0.578$ ).

Categorical analysis. There was no difference between subgroups with low, moderate or high SDCs at randomization, with respect to developing worsening HF during the 12 -week follow-up period. A total of 41 patients (30\%) experienced worsening HF during follow-up in the placebo group. The incidence of worsening HF during follow-up was similar in the SDC groups: $6 \%(\mathrm{n}=2)$ for the group with a randomization SDC between 0.5 and $0.9 \mathrm{ng} / \mathrm{ml}$ 
Table 1. Baseline Clinical Characteristics: Digoxin Withdrawal Versus Digoxin Continuation by Tertile of SDC Before Randomization

\begin{tabular}{|c|c|c|c|c|c|}
\hline \multirow[b]{2}{*}{ Characteristic } & \multirow{2}{*}{$\begin{array}{l}\text { All Digoxin WD/ } \\
\text { Any SDC }\end{array}$} & \multicolumn{3}{|c|}{ Digoxin Continuation } & \multirow[b]{2}{*}{ p Value } \\
\hline & & $\leq 0.9 \mathrm{ng} / \mathrm{ml}$ & $>0.9-1.2 \mathrm{ng} / \mathrm{ml}$ & $>1.2 \mathrm{ng} / \mathrm{ml}$ & \\
\hline \multicolumn{6}{|l|}{ Gender } \\
\hline Male & $113(81 \%)$ & $27(84 \%)$ & $33(75 \%)$ & $38(75 \%)$ & 0.562 \\
\hline Female & $26(19 \%)$ & $5(16 \%)$ & $11(25 \%)$ & $13(25 \%)$ & \\
\hline \multicolumn{6}{|l|}{ NYHA functional class } \\
\hline I & $3(2 \%)$ & $1(3 \%)$ & $2(5 \%)$ & & 0.093 \\
\hline II & $106(76 \%)$ & $26(81 \%)$ & $27(61 \%)$ & $39(76 \%)$ & \\
\hline III & $30(22 \%)$ & $4(13 \%)$ & $15(34 \%)$ & $12(24 \%)$ & \\
\hline \multicolumn{6}{|l|}{ Primary etiology } \\
\hline IHD & $83(60 \%)$ & $19(59 \%)$ & $31(70 \%)$ & $30(59 \%)$ & 0.597 \\
\hline Non-IHD & $56(40 \%)$ & $13(41 \%)$ & $13(30 \%)$ & $21(41 \%)$ & \\
\hline Age (yrs) & $61 \pm 1.0$ & $61 \pm 2.2$ & $62 \pm 1.6$ & $65 \pm 1.4$ & 0.383 \\
\hline $\mathrm{SDC}(\mathrm{ng} / \mathrm{ml})$ & $1.1 \pm 0.03$ & $0.8 \pm 0.02$ & $1.1 \pm 0.08$ & $1.5 \pm 0.03$ & $<0.001$ \\
\hline LVEF (U) & $28 \pm 0.8$ & $29 \pm 2.2$ & $24 \pm 1.4$ & $26 \pm 1.6$ & 0.085 \\
\hline CT ratio & $0.53 \pm 0.01$ & $0.52 \pm 0.01$ & $0.54 \pm 0.01$ & $0.54 \pm 0.01$ & 0.438 \\
\hline Duration of HF (yrs) & $3.5 \pm 0.4$ & $3.7 \pm 0.7$ & $4.1 \pm 0.6$ & $4.9 \pm 0.6$ & 0.242 \\
\hline $\begin{array}{l}\text { Supine systolic blood pressure } \\
\quad(\mathrm{mm} \mathrm{Hg})\end{array}$ & $126 \pm 1.5$ & $128 \pm 3.6$ & $125 \pm 2.7$ & $127 \pm 2.2$ & 0.643 \\
\hline Supine pulse (beats/min) & $76 \pm 1.1$ & $76 \pm 1.9$ & $77 \pm 1.9$ & $74 \pm 1.9$ & 0.798 \\
\hline Exercise duration (s) & 542 & 524 & 491 & 414 & 0.220 \\
\hline 6-minute walk $(\mathrm{ft})$ & 1,155 & 1,087 & 1,190 & 1,080 & 0.751 \\
\hline
\end{tabular}

versus $9 \%(\mathrm{n}=4)$ in the group with $\mathrm{SDC}$ values between $>0.9$ and $1.2 \mathrm{ng} / \mathrm{ml}$ and $12 \%(\mathrm{n}=6)$ in the group with $\mathrm{SDC}>1.2 \mathrm{ng} / \mathrm{ml}(\mathrm{p}>0.05)$. Unadjusted Cox proportional hazards analysis of the follow-up data demonstrated that the risk of treatment failure was significantly greater for patients withdrawn from digoxin therapy $(p<0.030)$, compared with patients who continued digoxin in any of the three randomization SDC groups. Multivariable Cox analysis demonstrated that the risk of worsening $\mathrm{HF}$ was significantly less (all $\mathrm{p}<0.020)$ for all subgroups of patients who continued digoxin after adjustment for LVEF, cardiothoracic ratio, age, $\mathrm{HF}$ score and angiotensin-converting enzyme inhibitor use (Table 3, Fig. 2). Specifically, patients in the low SDC category were significantly less likely than placebo patients to experience worsening $\mathrm{HF}$ during follow-up ( $\mathrm{p}=0.018)$. A similar analysis, which added distance walked in $6 \mathrm{~min}$ at baseline to the previous model, also demonstrated that the risk of worsening $\mathrm{HF}$ was significantly less for patients randomized to continue digoxin, regardless of $\mathrm{SDC}$ at randomization (all $\mathrm{p}<$ $0.020)$.

Median changes in maximal treadmill exercise time during follow-up in the various SDC subgroups are shown in Figure 3. After 12 weeks, patients continuing digoxin in the lowest SDC group at randomization had a significantly greater change (median $+5.5 \mathrm{~s}$ ) in exercise time, compared with patients withdrawn from digoxin (median $-46 \mathrm{~s}, \mathrm{p}=$ 0.015). A median change in exercise capacity was similar after 12 weeks among patients in the low $(+5.5 \mathrm{~s})$, moderate $(+33 \mathrm{~s})$ and high $(-1 \mathrm{~s})$ SDC groups (all $\mathrm{p}>0.078)$.

Table 2. Digoxin Dosages and Corresponding SDCs in the Study Treatment Groups

\begin{tabular}{|c|c|c|c|c|c|c|c|c|}
\hline \multirow[b]{3}{*}{ Time Point } & \multirow{2}{*}{\multicolumn{2}{|c|}{$\begin{array}{l}\text { All Digoxin WD/ } \\
\text { Any SDC }\end{array}$}} & \multicolumn{6}{|c|}{ Digoxin Continuation } \\
\hline & & & \multicolumn{2}{|c|}{$\leq 0.9 \mathrm{ng} / \mathrm{ml}$} & \multicolumn{2}{|c|}{$>0.9-1.2 \mathrm{ng} / \mathrm{ml}$} & \multicolumn{2}{|c|}{$>1.2 \mathrm{ng} / \mathrm{ml}$} \\
\hline & $\begin{array}{c}\text { Dose } \\
\text { (mg/day) }\end{array}$ & $\underset{(\mathrm{ng} / \mathrm{ml})}{\mathrm{SDC}}$ & $\begin{array}{c}\text { Dose } \\
(\mathrm{mg} / \text { day })\end{array}$ & $\underset{(\mathrm{ng} / \mathrm{ml})}{\mathrm{SDC}}$ & $\begin{array}{c}\text { Dose } \\
\text { (mg/day) }\end{array}$ & $\underset{(\mathrm{ng} / \mathrm{ml})}{\mathrm{SDC}}$ & $\begin{array}{c}\text { Dose } \\
\text { (mg/day) }\end{array}$ & $\begin{array}{l}\mathrm{SDC} \\
(\mathrm{ng} / \mathrm{ml})\end{array}$ \\
\hline Baseline* & $0.21 \pm 0.01$ & $0.54 \pm 0.06$ & $0.22 \pm 0.01$ & $0.45 \pm 0.11$ & $0.23 \pm 0.01$ & $0.69 \pm 0.08$ & $0.22 \pm 0.01$ & $0.78 \pm 0.12$ \\
\hline Before randomization $\dagger$ & $0.37 \pm 0.01$ & $1.11 \pm 0.03$ & $0.38 \pm 0.02$ & $0.78 \pm 0.02$ & $0.37 \pm 0.02$ & $1.09 \pm 0.01$ & $0.34 \pm 0.02$ & $1.52 \pm 0.03$ \\
\hline $\begin{array}{l}\text { Change from baseline to } \\
\text { pre-randomization }\end{array}$ & $0.15 \pm 0.01$ & $0.57 \pm 0.06$ & $0.16 \pm 0.02$ & $0.33 \pm 0.10$ & $0.14 \pm 0.01$ & $0.40 \pm 0.08$ & $0.13 \pm 0.01$ & $0.73 \pm 0.12$ \\
\hline End point & - & - & $0.42 \pm 0.02$ & $0.90 \pm 0.04$ & $0.40 \pm 0.03$ & $1.14 \pm 0.09$ & $0.39 \pm 0.03$ & $1.25 \pm 0.08$ \\
\hline $\begin{array}{l}\text { Change from } \\
\text { pre-randomization to } \\
\text { end point }\end{array}$ & - & - & $0.01 \pm 0.01$ & $0.13 \pm 0.04$ & $0.04 \pm 0.02$ & $0.05 \pm 0.09$ & $0.01 \pm 0.01$ & $-0.28 \pm 0.08$ \\
\hline
\end{tabular}

*At visit 1 . †At visit 6 . Treatment groups were classified by the pre-randomization serum digoxin concentration. Data are presented as the mean value \pm SEM. $\mathrm{SDC}=$ serum digoxin concentration; $\mathrm{WD}=$ withdrawal. 
Table 3. Risk of Treatment Failure Based on Randomization SDC Group

\begin{tabular}{lccr}
\hline \multicolumn{1}{c}{$\begin{array}{c}\text { Treatment } \\
\text { Group }\end{array}$} & $\begin{array}{c}\text { Relative } \\
\text { Risk }\end{array}$ & $\mathbf{9 5 \%}$ CI & p Value \\
\hline $\begin{array}{l}\text { Digoxin continued (SDC) } \\
\leq 0.9 \mathrm{ng} / \mathrm{ml}\end{array}$ & 0.09 & $0.01-0.66$ & 0.018 \\
$>0.9-1.2 \mathrm{ng} / \mathrm{ml}$ & 0.22 & $0.08-0.61$ & 0.004 \\
$>1.2 \mathrm{ng} / \mathrm{ml}$ & 0.17 & $0.06-0.44$ & $<0.001$ \\
\hline
\end{tabular}

Relative risk and $\mathrm{p}$ values are based on the adjusted Cox proportional hazards analysis $\mathrm{CI}=$ confidence interval; SDC $=$ serum digoxin concentration.

The change in LVEF from randomization to the last measured value for each of the four subgroups of SDC is shown in Figure 4. The change in LVEF for those patients who continued the drug was similar, regardless of SDC at randomization. Left ventricular ejection fraction declined significantly in patients withdrawn from digoxin $(-4.1 \pm$ $0.7 \mathrm{U})$, compared with patients who continued digoxin in the low $(1.4 \pm 1.1 \mathrm{U})$, moderate $(1.2 \pm 1.1 \mathrm{U})$ or high serum $(0.0 \pm 1.2 \mathrm{U})$ SDC groups (all $\mathrm{p}<0.005)$.

\section{DISCUSSION}

Although substantial evidence for a benefit of digoxin in patients with HF has accumulated over two centuries of use, culminating in the recent results of the study done by the Digitalis Investigation Group (15), previous work has not defined the SDC necessary for clinical efficacy. Our results, derived from the PROVED and RADIANCE trials, provide important new information on the serum concentration necessary for a therapeutic benefit in patients with HF. Our principal analysis failed to demonstrate any significant relationship between $\mathrm{SDC}$, as a continuous variable, and the clinical outcomes of patients in PROVED and RADIANCE. Patients taking digoxin did significantly better than those not taking the drug, but the serum concentration did not correlate with the outcome. This finding was confirmed by our secondary categorical analysis, which revealed favorable outcomes in patients treated with relatively low SDCs $(\leq 0.9 \mathrm{ng} / \mathrm{ml})$. Patients who continued digoxin in this range of serum concentrations had a similar risk of treatment failure and similar exercise capacity and maintained their LVEF, as well as patients who continued digoxin at higher serum concentrations. The lack of a relationship between $\mathrm{LV}$ function and SDC was anticipated, given the serum concentrations present in the patients in PROVED and RADIANCE and the previous results of dose-response studies of the effects of digoxin on $\mathrm{LV}$ function. However, and more importantly, the clinical outcomes of treadmill performance and risk of worsening $\mathrm{HF}$ in patients who continued digoxin were independent of the serum concentration, as well, and were superior in the categorical analysis of all specific SDC groups compared with the group

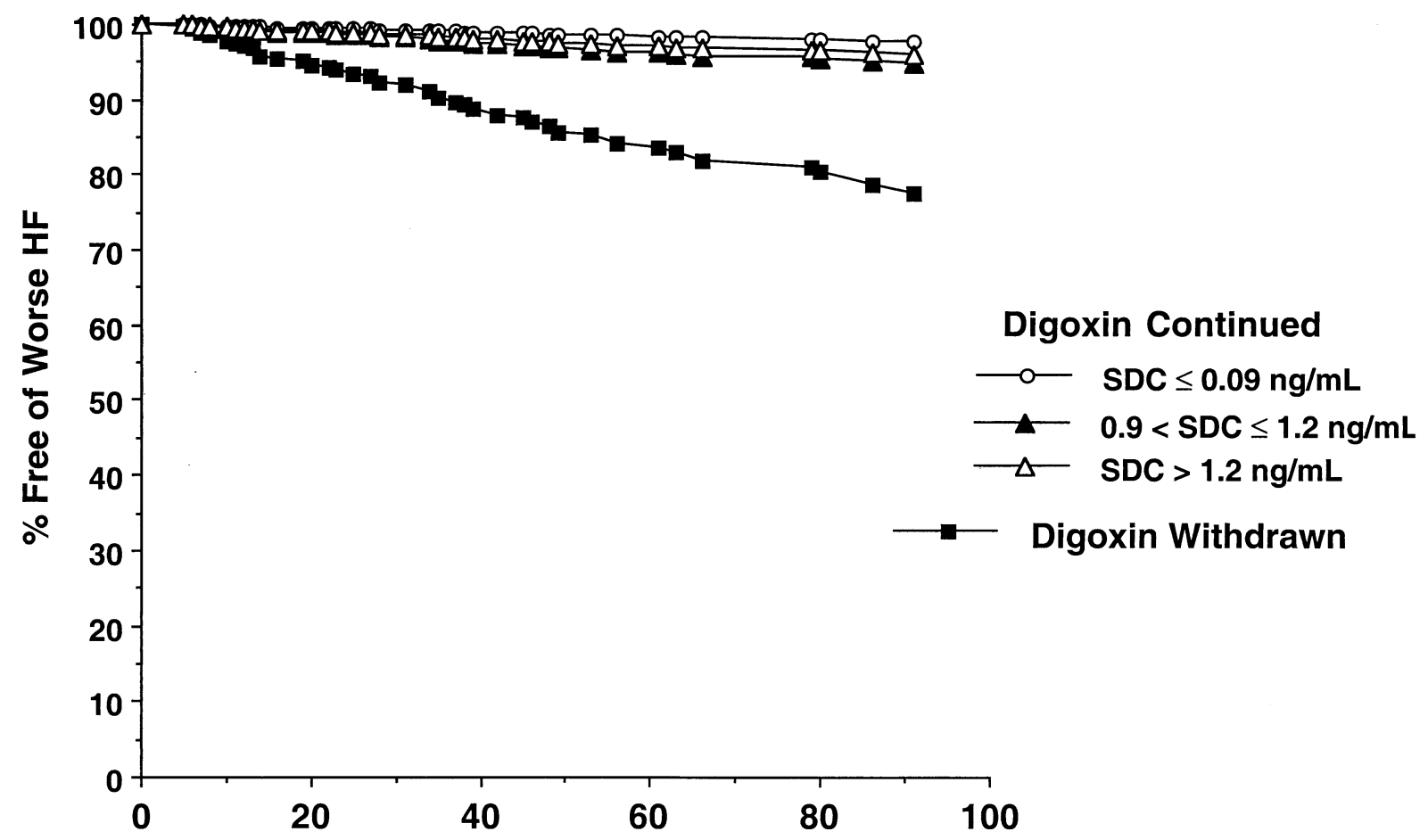

Days Post Randomization

Figure 2. Adjusted likelihood of worsening heart failure (HF) in the four patient groups defined by either withdrawal from digoxin or serum digoxin concentration (SDC) at randomization in those who continued the drug. Patients who continued digoxin in any category of serum concentration were significantly less likely (all $\mathrm{p}<0.02)$ to experience treatment failure than patients withdrawn from digoxin. 


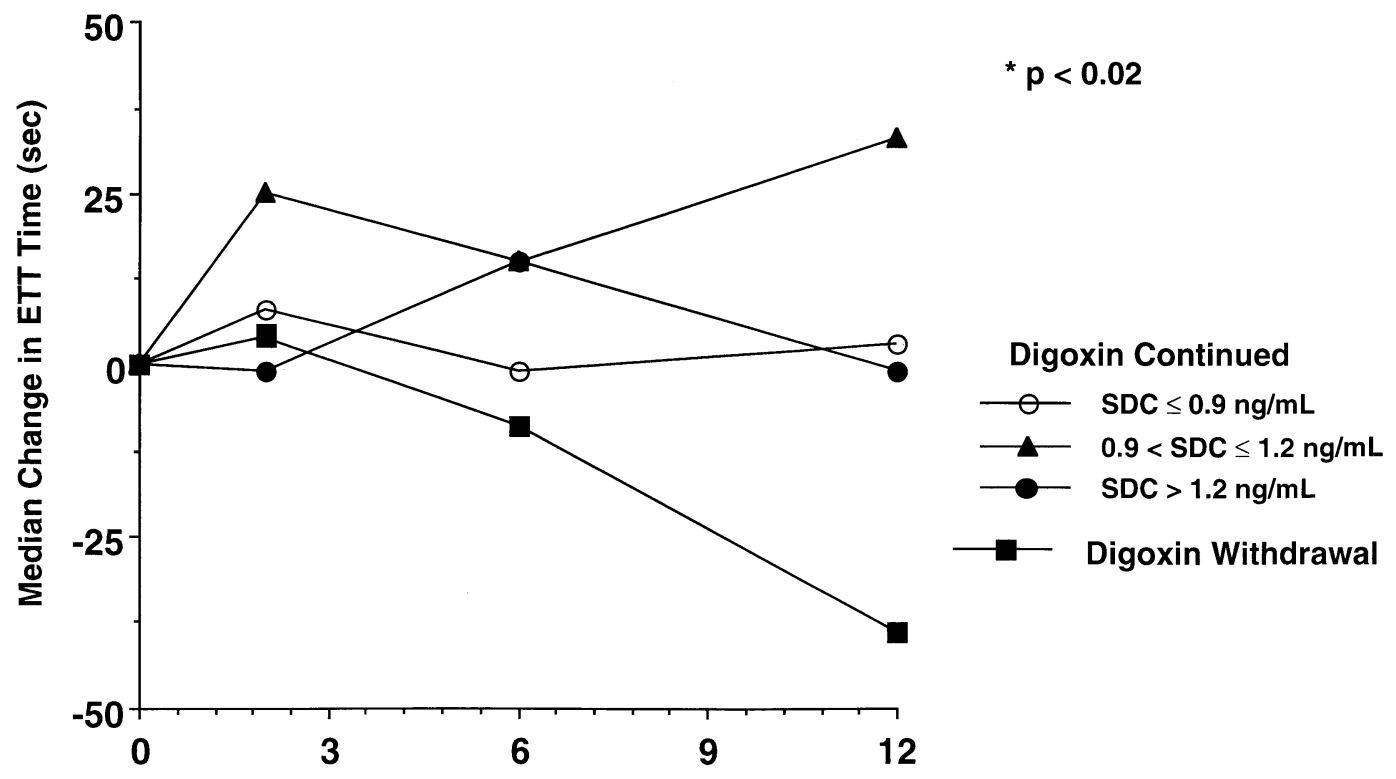

Weeks Post Randomization

Figure 3. Changes in maximal exercise treadmill test (ETT) duration in the four patient groups analyzed in the study. At the end of 12 weeks, patients who continued digoxin in each of the serum concentration groups had a significantly better exercise capacity than patients who discontinued digoxin $\left({ }^{*} \mathrm{p}\right.$ value for all three serum digoxin groups vs. placebo [digoxin withdrawal]). SDC = serum digoxin concentration.

withdrawn from digoxin. The absence of a significant relationship between clinical efficacy and SDC was also found when continuous or categorical analyses were performed utilizing the serum concentration determined at the final study visit.
Previous studies. Recommendations for target SDCs appear to have been originally derived from dose-response studies of the effect of digoxin on various indexes of ventricular function (16). Noninvasive indexes suggest an increase in ventricular function up to a steady-state serum

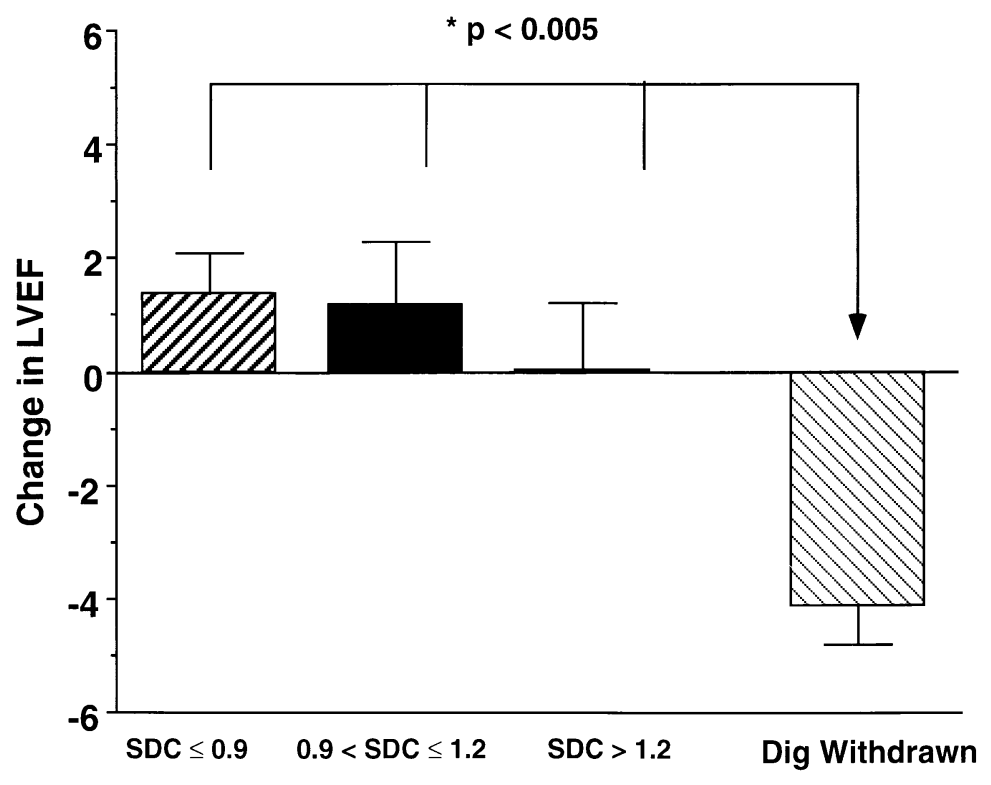

\section{Serum Digoxin Concentration Group $(\mathrm{ng} / \mathrm{mL})$}

Figure 4. Changes in left ventricular ejection fraction (LVEF) from randomization to the final study measurement in the four patient groups analyzed in the study. Left ventricular ejection fraction declined significantly in patients who discontinued digoxin (Dig), compared with patients who continued digoxin, regardless of the serum concentration at randomization (*all $\mathrm{p}<0.005)$. SDC $=$ serum digoxin concentration. 
concentration of $\sim 1.4 \mathrm{ng} / \mathrm{ml}$, with little or no further improvement as the serum concentration rises above this level (3-6). Increasing recognition that neurohormonal modulation is related to the clinical efficacy of digoxin suggests that dose-response relationships for this action should be considered, as well (17). Two recent studies provide important additional data on dose-response relationships for both ventricular function and the neurohormonal-modulating effects of digoxin. Gheorghiade et al. (10) demonstrated an increase of $\sim 3.5 \mathrm{U}$ in LVEF as SDC rose from $0.67 \pm 22 \mathrm{ng} / \mathrm{ml}$ to $1.22 \pm 0.35 \mathrm{ng} / \mathrm{ml}$, with increasing oral doses of digoxin in 22 patients with $\mathrm{HF}$ due to systolic dysfunction. This increase in LVEF was not accompanied by any change in $\mathrm{HF}$ score, exercise tolerance or plasma norepinephrine concentration. These results suggest a dissociation between the effects of digoxin on $\mathrm{LV}$ function and the neurohormonal actions of the drug. Slatton et al. (9) studied the short-term (two-week) effects of low $(0.125 \mathrm{mg} /$ day $)$ and moderate $(0.25 \mathrm{mg} /$ day $)$ doses of digoxin on indexes of $\mathrm{LV}$ function and neurohormonal status in 19 patients with moderate clinical HF and LVEF $<0.45$. Although data on the serum concentration were not reported, these investigators found that low-dose digoxin therapy increased ventricular performance, reduced the heart rate and increased heart rate variability. An increase to moderate-dose digoxin did not further reduce sympathetic activity, as assessed by heart rate variability or plasma norepinephrine concentration. Interestingly, these investigators demonstrated an increase in ventricular performance by several relatively load-independent indexes with low-dose digoxin and no further increase with moderate-dose digoxin. These two recent studies support the findings of the present study concerning the efficacy of low serum concentrations of digoxin.

Therapeutic considerations. Sudden death, most commonly due to presumed rapid ventricular arrhythmia, remains an important unresolved problem of patients with chronic HF (18). Despite beneficial hemodynamic effects, inotropic therapy for HF has been associated with an adverse effect on mortality, which appears to be related to an increased risk of sudden death. Data from several clinical trials support the concept that the increased risk of sudden death is dose-dependent-more likely to occur at higher doses (19-21). A similar analysis is under way for digoxin, based on the Digitalis Investigation Group's data, but has not yet been published. However, data already suggest that SDC $>1 \mathrm{ng} / \mathrm{ml}$ may be associated with classic digoxin toxicity (22-25). In addition, the findings of Williamson et al. (26) indicate that serum digoxin levels $>2.0 \mathrm{ng} / \mathrm{ml}$ still occur with some frequency $(9.3 \%)$ in clinical practice and cannot be attributed solely to sampling too close to the daily dose of digoxin. Results from our study and previous work reviewed by others (27) suggest that SDCs classically considered to be low are, in fact, effective in patients with HF due to systolic dysfunction. Hopefully, the use of doses of digoxin to achieve serum concentrations $\leq 0.9 \mathrm{ng} / \mathrm{ml}$ will be associated with reduced toxicity, as well as favorable clinical effects.
Study limitations. A prospective, randomized trial of doses designed to achieve various SDCs will be necessary to definitively establish the dose-response efficacy of digoxin in patients with HF. Patients who continued digoxin therapy in our study were not randomly assigned to predetermined SDC groups. This meant that a prospective determination of specific ranges of SDC for comparison was not possible, and that patients in different ranges of SDC may have been different at baseline. However, our principal analysis modeled SDC as a continuous variable to avoid the potential bias introduced by selection of arbitrary cut points. The results of our continuous analysis were subsequently confirmed by a secondary categorical analysis, based on specific subgroups of SDC defined by randomization values. In addition, patients in the various SDC subgroups were found to be similar with regard to a number of baseline characteristics evaluated. Multivariate analysis, which adjusted for several baseline characteristics that might have influenced the likelihood of treatment failure, demonstrated that $\mathrm{pa}^{-}$ tients in the lowest serum digoxin tertile, defined either by randomization or final study visit values, had a significantly lower risk of treatment failure, compared with patients withdrawn from digoxin.

The PROVED and RADIANCE trials had a withdrawal design. Withdrawal trials are inherently less rigorous tests of efficacy, compared with studies in which the drug being investigated is prospectively added at randomization. Interestingly, the results from the Digitalis Intervention Group trial, which enrolled patients both receiving (subsequent withdrawal subset) and not receiving digoxin (subsequent add-on subset) at baseline, support the overall efficacy findings demonstrated in PROVED and RADIANCE. The estimate of a clinical benefit from digoxin compared with placebo was similar among patients not taking digoxin at baseline (patients who had digoxin added did better than those who did not) and among patients who were taking digoxin at baseline (patients who continued digoxin did better than those who were withdrawn) (15).

Conclusions. In severe, symptomatic systolic dysfunction, evidence of a benefit from digoxin therapy was apparent, regardless of SDC. A secondary categorical analysis also demonstrated similar outcomes in patients who continued digoxin at low, moderate and high SDCs, compared with patients withdrawn from digoxin. These results support the possibility that a lower therapeutic goal for SDC is warranted in patients with $\mathrm{HF}$.

\section{Acknowledgment}

The authors gratefully acknowledge the efforts of Cynthia French in manuscript preparation.

Reprint requests and correspondence: Dr. Kirkwood F. Adams, Jr., Division of Cardiology, University of North Carolina at Chapel Hill, CB \#7075, Burnett-Womack Building, Chapel Hill, North Carolina 27599-7075. E-mail: kfa@med.unc.edu. 


\section{REFERENCES}

1. Gheorghiade M, Pitt B. Digitalis Investigation Group (DIG) trial: a stimulus for further research. Am Heart J 1997;134:3-12.

2. Gheorghiade M, Zarowitz BJ. Review of randomized trials of digoxin therapy in patients with chronic heart failure. Am J Cardiol 1992;69: 48G-63G.

3. Carliner NH, Gilbert CA, Pruitt AW, Goldberg LI. Effect of maintenance digoxin therapy on systolic time intervals and serum digoxin concentrations. Circulation 1974;50:94-8.

4. Hoeschen RJ, Cuddy TE. Dose-response relation between therapeutic levels of serum digoxin and systolic time intervals. Am J Cardiol 1975;35:469-72.

5. Buch J, Waldorff S. Classical concentration-response relationship between serum digoxin level and contractility indices. Dan Med Bull 1980;27:287-90.

6. Belz GG, Erbel R, Schumann K, Gilfrich HJ. Dose-response relationships and plasma concentrations of digitalis glycosides in man. Eur J Clin Pharmacol 1978;13:103-11.

7. van Veldhuisen DJ, Man in't Veld AJ, Dunselman PH, et al, on behalf of the DIMT Study Group. Double-blind placebo-controlled study of ibopamine and digoxin in patients with mild to moderate heart failure: results of the Dutch Ibopamine Multicenter Trial (DIMT). J Am Coll Cardiol 1993;22:1564-73.

8. Krum H, Bigger JT, Goldsmith RL, Packer M. Effect of long-term digoxin therapy on autonomic function in patients with chronic heart failure. J Am Coll Cardiol 1995;25:289-94.

9. Slatton ML, Irani WN, Hall SA, et al. Does digoxin provide additional hemodynamic and autonomic benefit at higher doses in patients with mild to moderate heart failure and normal sinus rhythm? J Am Coll Cardiol 1997;29:1206-13.

10. Gheorghiade M, Hall VB, Jacobsen G, Alam H, Rosman H, Goldstein S. Effects of increasing maintenance dose of digoxin on left ventricular function and neurohormones in patients with chronic heart failure treated with diuretics and angiotensin-converting enzyme inhibitors. Circulation 1995;92:1801-7.

11. Uretsky BF, Young JB, Shahidi FE, Yellen LG, Harrison MC, Jolly MK. Randomized study assessing the effect of digoxin withdrawal in patients with mild to moderate chronic congestive heart failure: results of the PROVED trial. J Am Coll Cardiol 1993;22:955-62.

12. Packer M, Gheorghiade M, Young JB, et al. Withdrawal of digoxin from patients with chronic heart failure treated with angiotensinconverting enzyme inhibitors. N Engl J Med 1993;329:1-7.
13. Woolson RF. Least squares regression methods: predicting one variable from another. In: Statistical Methods for the Analysis of Biomedical Data. New York, NY: John Wiley \& Sons, 1987, 280-313.

14. Adams KF, Gheorghiade M, Uretsky BF, et al. Patients with mild heart failure worsen during withdrawal from digoxin therapy. J Am Coll Cardiol 1997;30:42-8.

15. The Digitalis Investigation Group. The effect of digoxin on mortality and morbidity in patients with heart failure. N Engl J Med 1997;336: 525-33.

16. Hoeschen RJ, Cuddy TE. Dose-response relation between therapeutic levels of serum digoxin and systolic time intervals. Am J Cardiol 1975;35:469-72.

17. Gheorghiade M, Ferguson D. Digoxin: a neurohormonal modulator in heart failure? Circulation 1991;84:2181-6.

18. Stevenson WG, Sweeney MO. Arrhythmias and sudden death in heart failure. Jpn Circ J 1997;61:727-40.

19. The Xamoterol in Severe Heart Failure Study Group. Xamoterol in severe heart failure. Lancet 1990;336:1-6.

20. Packer M, Carver JR, Rodeheffer RJ, et al, for the PROMISE Study Research Group. Effect of oral milrinone on mortality in severe chronic heart failure. N Engl J Med 1991;325:1468-75.

21. Cohn JN, Goldstein SO, Greenberg BH, et al, for the Vesnarinone Trial Investigators. A dose-dependent increase in mortality with vesnarinone among patients with severe heart failure. N Engl J Med 1998;339:1810-6.

22. Kelly RA, Smith TW. Recognition and management of digitalis toxicity. Am J Cardiol 1992;69:108G-19G.

23. Warren JL, McBean AM, Hass SL, Babish JD. Hospitalizations with adverse events caused by digitalis therapy among elderly medicare beneficiaries. Arch Intern Med 1994;154:1482-7.

24. Mahdyoon H, Battilana G, Rosman H, Goldstein S, Gheorghiade M. The evolving pattern of digoxin intoxication: observations at a large urban hospital from 1980 to 1988. Am Heart J 1990;120:1189-94.

25. Smith TW, Haber E. Digoxin intoxication: the relationship of clinical presentation to serum digoxin concentration. J Clin Invest 1970;49: 2377-86.

26. Williamson KM, Thrasher KA, Fulton KB, et al. Digoxin toxicity: an evaluation in current clinical practice. Arch Intern Med 1998;158: 2444-9.

27. van Veldhuisen DJ, de Graeff PA, Remme WJ, Lie KI. Value of digoxin in heart failure and sinus rhythm: new features of an old drug? J Am Coll Cardiol 1996;28:813-9. 